\title{
The costs of breed reconstruction from cryopreserved material in mammalian livestock species
}

\author{
Gustavo GANDINI $^{\mathrm{a} *}$, Flavia PIZzI $^{\mathrm{b}}$, Alessandra STELla $^{\mathrm{c}}$, \\ Paul J. BOETTCHER ${ }^{b, d}$ \\ ${ }^{a}$ Department VSA, Università degli Studi di Milano, Milan, Italy \\ ${ }^{b}$ Instituto di Biologia e Biotecnologia Agraria, CNR, Milan, Italy \\ ${ }^{\mathrm{c}}$ CERSA-Parco Tecnologico Padano, Lodi, Italy \\ ${ }^{\mathrm{d}}$ IAEA/FAO Joint Division for Nuclear Techniques in Food and Agriculture, Vienna, Austria
}

(Received 9 August 2006; accepted 9 January 2007)

\begin{abstract}
The aim of this work was to compare costs, in the horse, cattle, sheep, swine, and rabbit species, for the creation of gene banks for reconstruction of an extinct breed, using different strategies: embryos-only, embryos in combination with semen, and semen-only. Three cost measures were used: time required for population reconstruction, cost for creation of the gene bank, number of years-keeping-female to reach reconstruction. Semen costs were estimated across four scenarios: the presence or absence of a commercial market for semen, purchase of semen donors, and semen extracted from the epididymus. The number of cells were doubled to take into account the creation of two storage sites. The strategy embryos-only required the shortest time to reach reconstruction. With the strategy embryos + semen, time increased with decreasing proportions of embryos. With semen-only, reconstruction time varied from 2 to 21 years. A high variation of costs was observed across species and strategies, from 360 Euros in the rabbit to 1092300 in the horse. In all species, the embryos-only strategy was about $10 \%$ more expensive than using $90 \%$ embryos + semen. Decreasing the percentage of embryos further diminished costs. The number of years-keeping-female ranged across strategies, from 2 in the rabbit, to a maximum of 12878 in the horse.
\end{abstract}

conservation cost / genetic conservation / breed reconstruction / gene bank / mammalian livestock

\section{INTRODUCTION}

Cryopreservation is an important tool complementary to in situ conservation, as genetic back-up in case of losses of genetic variation, and it is the

\footnotetext{
*Corresponding author: gustavo.gandini@unimi.it
} 
strategy of choice when in situ strategies are ineffective in avoiding excessive losses of genetic variation or breed extinction. Semen and embryos have both been proposed for operational cryopreservation of farm animal genetic resources $[4,5]$, considering that freezing oocytes is routinely available only in cattle and that cloning technologies are not yet sufficiently developed to allow for the routine use of somatic cells for re-establishing livestock populations. However, when reconstruction of the extinct breed is the aim of cryostorage, both strategies have some limitations: (i) with low fertility species the number of doses of semen needed can be very high; (ii) in breeds of small population size, due to the scarcity of female donors, it might be impossible to obtain the embryos needed; (iii) with semen, the whole genome can not be recovered and cytoplasmic effects will be lost or altered. In order to overcome these constraints, the use of combinations of semen and embryo storage has been proposed.

Designing efficient cryo-banking systems requires one to consider costs. However, the literature on cryopreservation costs is scant and dated $[3,9,11,16]$. Costs of embryo and semen banks seem to vary consistently among species [12]. Average costs for creating swine semen banks were similar among four European countries [10] but high variability among breeds within countries can be observed [6].

The aim of this work was to compare the costs for the creation of gene banks using three different strategies: (1) embryos-only; (2) embryos in combination with semen [2]; and (3) semen-only [12]. In this study, the general aim of cryopreservation was the creation of gene banks for reconstruction of an extinct breed. Cost analysis included both the creation of the gene bank and the resources needed for breed reconstruction. Other aims such as cryostorage to minimise genetic drift in small populations [17] or to store specific genotypes [15] will require different strategies that are not considered here.

\section{MATERIALS AND METHODS}

\subsection{Gene banks}

Stochastic and deterministic simulations were used to estimate the amount of genetic material to be cryopreserved for reconstructing a population of 25 females and 25 males of reproductive age, corresponding to an effective population size of 50, considering each of the three alternative strategies. The collection of enough semen and/or embryos to accommodate creation of duplicate banks was considered, as internationally suggested to minimise risk associated with natural disasters or simple accidents $[4,5]$. 
Table I. Reproductive parameters of the six species simulated.

\begin{tabular}{ccccccc}
\hline & Cattle & Horse & Sheep & Swine & Rabbit & Cattle-ET \\
\hline $\begin{array}{c}\text { Litter size } \\
\text { (mean; } D S \text { ) }\end{array}$ & $1.0 ; 0.0$ & $1.0 ; 0.0$ & $1.4 ; 0.5$ & $7.5 ; 2.5$ & $7.5 ; 2.5$ & $2.6 ; 2.0$ \\
$\begin{array}{c}\text { Age at maturity } \\
\text { (months) }\end{array}$ & 15 & 18 & 9 & 8 & 4 & 15 \\
$\begin{array}{c}\text { Parturition interval } \\
\text { (months) }\end{array}$ & 12 & 14.5 & 7 & 6 & 2.5 & 12 \\
$\begin{array}{c}\text { Pregnancy length } \\
\text { (months) }\end{array}$ & 9 & 11 & 5 & 4 & 1 & 9 \\
\hline
\end{tabular}

This study considered creation of banks for five mammalian species: the horse, cattle, sheep, swine and rabbit. In addition, in cattle the use of a reproductive technology increasing fecundity, multiple ovulation and embryo transfer, was simulated (cattle-ET) for a total of six "species" considered. The species varied according to mean and variation of family size, age at reproductive maturity, parturition interval and pregnancy length (Tab. I). Parameters common to all simulated species and strategies during reconstruction were conception rate ( 0.50 with semen and 0.40 with embryos), sex ratio at birth $(0.50)$ and survival rates of 0.8 from birth to first conception, 0.9 from conception to first parturition; and $0.86,0.8,0.75,0.75,0.7,0.7,0.65$, and 0.5 between each successive pair of parturitions up to a maximum of nine. These parameters were based on results typically observed under controlled conditions in industrialised countries. We assumed that the reconstructed population of animals would be considered highly valuable, and thus managed with good husbandry practices. This practice would allow these reproductive and survival rates to be easily obtained, regardless of the location.

\subsubsection{Embryos-only strategy}

The expected number of embryos needed to reconstruct a population of 25 females of breeding age exclusively using embryos was computed as

$$
\mathrm{E}\left(\mathrm{EMn}_{25}\right)=25 /(\mathrm{pf} \times \mathrm{c} \times \mathrm{sr} \times \mathrm{sb}),
$$

where $\mathrm{pf}$ is the probability that the embryo was female; $\mathrm{c}$ is the conception rate with embryo; $\mathrm{sr}$ and $\mathrm{sb}$ respectively the probabilities of survival of the recipient until parturition and of the embryo from birth to breeding age. With non-sexed embryos we expect to obtain also 25 males of breeding age. The number of embryos needed to reconstruct the population with a $90 \%$ rate of 
certainty (E90(EM $\left.\mathrm{n}_{25}\right)$ ) was computed assuming a normal approximation to the binomial distribution of the number of females obtained from embryos [2].

\subsubsection{Embryos + semen strategy}

The amount of genetic material to construct gene banks of different combinations of embryos and semen (embryos + semen) was estimated using a stochastic simulation designed by Boettcher et al. [2]. Each combination of embryos + semen was expressed as a percentage of the embryos needed to reconstruct with $90 \%$ certainty a breed using only embryos. This percentage ranged from $90 \%$ to $10 \%$. The number of doses of semen increased as the proportion of embryos decreased. The 25 donors were distributed as 22 females and 3 males in the strategy with $90 \%$ embryos, down to only 2 females and 23 males in the strategy with $10 \%$ embryos. The basic scheme of the simulation was to begin with a set of frozen embryos, for which survival to breeding age was simulated as for the strategy embryos-only. Then, all surviving females were inseminated with semen stored in the bank to produce offspring and survival was simulated. Insemination and survival processes were repeated until the reconstruction goal of 25 animals from each sex had been reached. Each simulation was replicated 500 times to obtain the expected and $90^{\text {th }}$ percentile values.

\subsubsection{Semen-only strategy}

Breed reconstruction by using semen-only is accomplished through a series of back-cross generations. The amount of semen required is a function of both species demography and breeding scheme. The expected number of doses of semen to reconstruct a population of 25 females of breeding age with semenonly was computed, following Ollivier and Renard [12], as:

$$
\mathrm{E}\left(\mathrm{SMn}_{25}\right)=\mathrm{d} \times \mathrm{F} \times \mathrm{np},
$$

where: $\mathrm{d}$ is the number of doses needed per parturition; $\mathrm{F}$ is the number of females to be inseminated during the reconstruction process, computed as $25 \times\left(\mathrm{r}+\mathrm{r}^{2}+\ldots+\mathrm{r}^{\mathrm{n}}\right)$, where $\mathrm{r}=(1 / \mathrm{f}), \mathrm{f}$ is the expected lifetime production of fertile daughters by female, and $\mathrm{n}$ is the number of generations of grading up; $\mathrm{np}$ is the number of parturitions to obtain the expected lifetime production of fertile daughters by female, which is a function of species demography and of the maximum number of parturitions allowed before culling (MAXP). 
With unsexed semen, at the end of the reconstruction process we also expect 25 males. The number of generations of grading up (n), where generation 1 is the $\mathrm{F} 1$ cross, and generation $\mathrm{n}$ is the $\mathrm{n}-1$ backcross generation, determines the expected proportion $\left(1-0.5^{\mathrm{n}}\right)$ of genes of the frozen semen present in the last backcross generation. A reconstruction scheme with five generations of backcrossing was generally assumed, corresponding to an expected recovery of $97 \%$ (standard deviation of 0.014 ) of the original genome in the reconstructed population [8]. A MAXP from one to five was simulated.

\subsection{Costs}

Three cost measures were used to compare the three banking strategies: time required for population reconstruction, cost for creation of the gene bank and number of years-keeping-females required to reach reconstruction. These measures are explained in more detail in the subsequent paragraphs.

Time needed for breed reconstruction is a function of reproductive and demographic parameters and the reconstruction scheme of both species. For the strategies embryos-only and embryos + semen, it was measured from the time of embryo implantation to the moment in which the population of 25 females and 25 males of reproductive age was obtained. For the strategy semen-only, it was measured from the conception of F1 crosses to the moment in which the population of 25 females and 25 males of reproductive age was obtained.

Costs for creation of the gene bank were based on costs of obtaining and freezing of semen and embryos. Semen costs were estimated across four scenarios. The first scenario assumed the presence of an existing market for the breed semen. The costs were based on the simple cost of purchasing semen doses (s-com). In other words, semen was assumed to have already been collected by another commercial entity. The second scenario assumed the absence of a market for the semen, so costs were based on unitary cost of collection and number of collections (s-nocom). The costs for the first collection included health tests; quarantine and training periods for a total of 60 (horse, cattle, pig) or 45 days (sheep, rabbit); collection and processing of the whole ejaculate. Costs for subsequent collections included the time elapsed between collections (one day in cattle, sheep, rabbit; 3 days in the horse, pig), collection and processing of the whole ejaculate. Production of 5, 200, 15, 20 and 10 doses of semen per ejaculate, respectively in the horse, cattle, sheep, pig and rabbit, was assumed. Semen costs assumed the use of equipment available in commercial AI stations. The third scenario assumed commercial semen costs in addition to costs to buy the donor males (s-com + donors). Costs of transport of animals 
Table II. Unitary costs of semen, embryos and donor animals used in the simulation, in Euros.

\begin{tabular}{|c|c|c|c|c|c|c|}
\hline & & Cattle & Horse & Sheep & Pig & Rabbit \\
\hline Ejaculated & Commercial dose & $1(0.5-2)$ & $40(35-50)$ & $5(4-7)$ & $9(5-15)$ & $3(1.5-4)$ \\
\hline \multirow{2}{*}{ semen } & Collection $\left(1^{\text {st }}\right)^{2}$ & 965 & 1406 & 361 & 835 & 146 \\
\hline & Collection $\left(>1^{\text {st }}\right)^{3}$ & 53 & 82 & 21 & 54 & 18 \\
\hline $\begin{array}{l}\text { Epididymal } \\
\text { semen }\end{array}$ & & 0.8 & & 1 & 15 & \\
\hline Embryos & In vivo & 100 & 600 & 70 & 80 & 6 \\
\hline Donors & & 1688 & 1688 & 300 & 270 & 6.8 \\
\hline
\end{tabular}

${ }^{1}$ In brackets, range observed across the expert panel.

${ }^{2}$ Cost of first collection includes health tests, quarantine, training, collection and processing of the whole ejaculate.

${ }^{3}$ Cost of each subsequent collection includes time elapsed between collections, collection and processing of the whole ejaculate.

to the AI station were excluded because they can vary consistently as a function of the distance to be covered. Organisation and logistic costs were not internalised. Proportions of animals acquired, trained and failing to become donors were $0.1,0.35,0.4,0.2,0.1$ respectively in cattle, horse, sheep, pig and rabbit and their costs were taken into account. The fourth scenario assumed that semen was simply extracted from the epididymus of slaughtered animals (s-epidid), and it was simulated only in the species where the efficiency of the technique has been demonstrated: cattle [13], small ruminants [1] and the pig [14]. Costs included extraction of spermatozoa, processing and freezing, and assumed a potential production, per pair of testis, of 200, 150 and 10 doses of semen respectively in cattle, sheep and the pig. The cost of initially obtaining the testes were not considered.

Embryo costs included hormonal treatment, collection at the farm, processing and freezing, and assumed the use of available equipment in commercial laboratories.

Unitary costs for ejaculated semen and embryos were estimated from information collected by a panel of experts in Austria, France, Great Britain, Italy, and the Netherlands, and are reported in Table II. The costs of epididymal semen were estimated in Italy (Tab. II).

The third parameter was the number of years-keeping-females during reconstruction (Years-FF), i.e. the cumulative number of years of herd-life for the females raised during breed reconstruction. This parameter is a function of the number of females to be raised and of the average age at culling/death, 
Table III. Number of donors, embryos, and doses of semen for cryostorage, as a function of strategy and species ${ }^{1,2}$.

\begin{tabular}{|c|c|c|c|c|c|c|c|}
\hline Strategy & \multicolumn{3}{|c|}{ All species } & Cattle / Horse & Sheep & Pig / Rabb & Cattle-ET \\
\hline & \multicolumn{3}{|c|}{$\begin{array}{l}\text { Female Male Embryos } \\
\text { donors donors }\end{array}$} & \multicolumn{4}{|c|}{ Doses of semen } \\
\hline Embryos-only & 25 & & $348-430$ & & & & \\
\hline $\begin{array}{c}\text { Embryos + semen } \\
\% \text { embryos }\end{array}$ & & & & & & & \\
\hline 90 & 22 & 3 & 388 & $22-96$ & $14-48$ & $4-14$ & $6-30$ \\
\hline 80 & 20 & 5 & 344 & $50-150$ & $28-88$ & $8-20$ & $14-54$ \\
\hline 70 & 17 & 8 & 300 & $88-184$ & $52-112$ & $12-24$ & $36-84$ \\
\hline 60 & 15 & 10 & 258 & $126-248$ & $72-122$ & $16-28$ & $52-96$ \\
\hline 50 & 12 & 13 & 216 & $216-408$ & $90-128$ & $22-34$ & $76-120$ \\
\hline 40 & 10 & 15 & 172 & $274-472$ & $102-144$ & $28-48$ & $98-138$ \\
\hline 30 & 7 & 18 & 130 & $370-612$ & $130-200$ & $32-52$ & $100-128$ \\
\hline 20 & 5 & 20 & 86 & $452-682$ & $130-198$ & $36-56$ & $92-120$ \\
\hline 10 & 2 & 23 & 44 & $512-740$ & $154-212$ & $32-48$ & $78-108$ \\
\hline $\begin{array}{l}\text { Semen-only } \\
\text { MAXP }^{4}\end{array}$ & & 25 & & & & & \\
\hline 5 & & & & 1172 & & & \\
\hline 4 & & & & 1272 & 798 & & \\
\hline 3 & & & & 1664 & 822 & & \\
\hline 2 & & & & 3620 & 1134 & & 484 \\
\hline 1 & & & & 25684 & 5998 & 260 & 612 \\
\hline
\end{tabular}

${ }^{1}$ Expected values. In italics, for embryos-only and embryos + semen strategies, $90 \%$ percentile.

${ }^{2}$ Material for the creation of two storage sites.

${ }^{3}$ Percentage of embryos with respect to the amount of the embryos-only $-90 \%$ percentile.

${ }^{4}$ MAXP, maximum number of parturitions allowed during reconstruction before culling.

which with the strategy semen-only was predefined (MAXP). The pregnancy of recipients was not considered for the founder embryos (embryos-only and embryos + semen strategies) nor in the case of cattle-ET.

\section{RESULTS AND DISCUSSION}

Table III compares the amount of genetic material needed to reconstruct a population of 25 females and 25 males of reproductive age across the simulated banking strategies and species. The numbers of embryos and semen doses were doubled to take into account the creation of two storage sites. With the strategy 


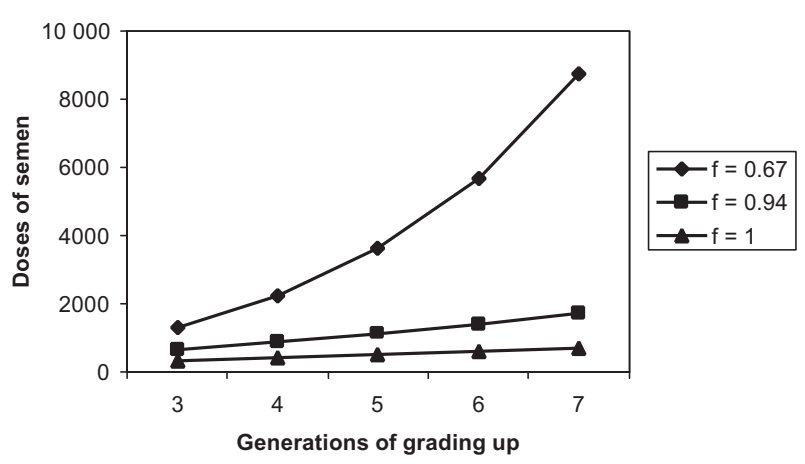

Figure 1. Number of doses of semen for breed reconstruction, as a function of the number of generations of grading up and lifetime production of fertile daughters by females (f).

embryos-only the expected number of embryos was 348 in all species, and 430 considering the $90^{\text {th }}$ percentile. In the strategy embryos + semen, one dose of semen replaced on average $0.7,2.5,9.5$ and 2.7 embryos, respectively in cattle and horses, sheep, pigs and rabbits, and cattle-ET. In the strategy embryos + semen, simulated stochastically, $90^{\text {th }}$ percentiles of the number of doses of semen were from 1.4 to 4 greater than the expected values.

With the strategy semen-only, the number of doses of semen increased exponentially when decreasing MAXP in nonprolific species such as the horse, cattle and sheep. In cattle, using reproductive technologies (cattle-ET) decreased the number of doses of semen by as much as 42 times (when MAXP $=1$ ).

Although five generations of grading up were used to compare the semenonly strategy with the two approaches using embryos (Tab. III), the influence of the number of backcross generations on the number of doses of semen needed was also examined. Figure 1 shows how the number of generations of grading up affects the number of doses of semen, by comparing populations with different lifetime production of fertile daughters by females (f) across reconstruction schemes of 3 to 7 generations of grading up. By increasing the number of generations of backcrossing, the number of doses increased linearly when $f=1$ and exponentially when $\mathrm{f}<1$.

Figure 2 shows the number of years needed to reconstruct the breed according to banking strategy and species. The strategy embryos-only required the shortest time, from 5 months (rabbit) to 2.4 years (horse), respectively. With the strategy embryos + semen, the time for reconstruction increased with decreasing proportions of embryos, especially for nonprolific species. With semen-only, reconstruction time increased with MAXP. Extending MAXP 


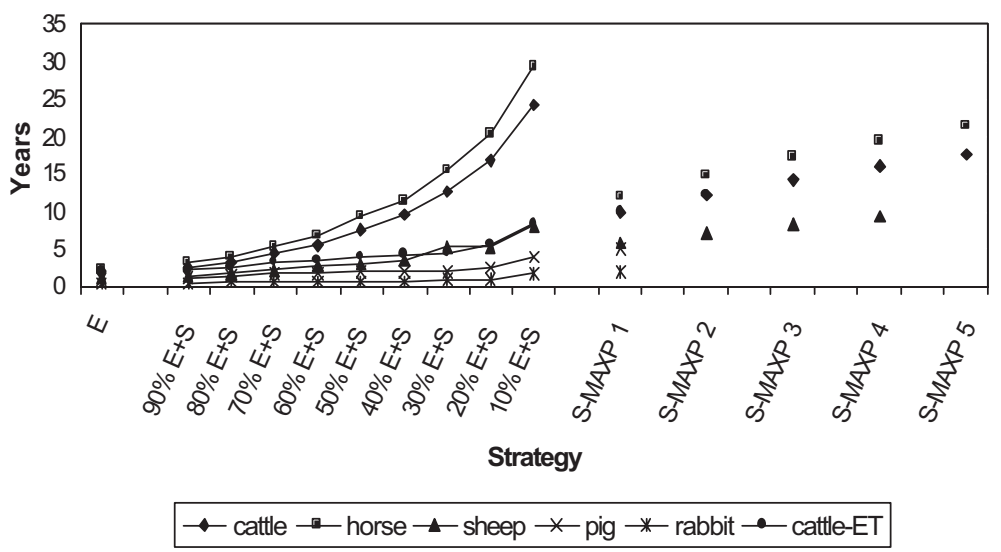

Figure 2. Number of years needed to reconstruct the breed, according to banking strategy $(\mathrm{E}=$ embryos-only; $\% \mathrm{E}+\mathrm{S}=\%$ embryos + semen; S-MAXP $\mathrm{n}=$ semenonly - maximum number of parturitions before culling) and species.

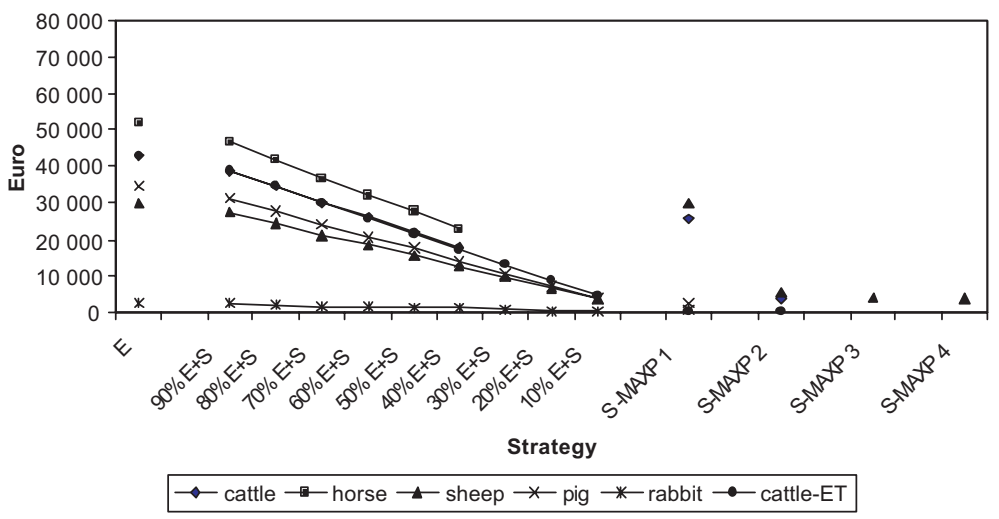

Figure 3. Costs (Euros) for the creation of the cryo-bank, across strategies $(\mathrm{E}=$ embryos-only; \% E+S = \% embryos + semen; S-MAXP $\mathrm{n}=$ semen-only - maximum number of parturitions before culling) and species. Semen costs assume the commercial scenario. Horse values are divided by 5 .

from 1 to 3 (horse, cattle, sheep) increased the time for reconstruction by approximately $45 \%$.

Figure 3 reports the expected costs, in Euro, for the creation of the cryo-bank across strategies and species, using the s-com scenario for semen. Comparisons were limited to situations where breed construction could be accomplished within a reasonable time of 12 years, on average. In all species, embryos-only was about $10 \%$ more expensive than using $90 \%$ embryos + semen. Decreasing 


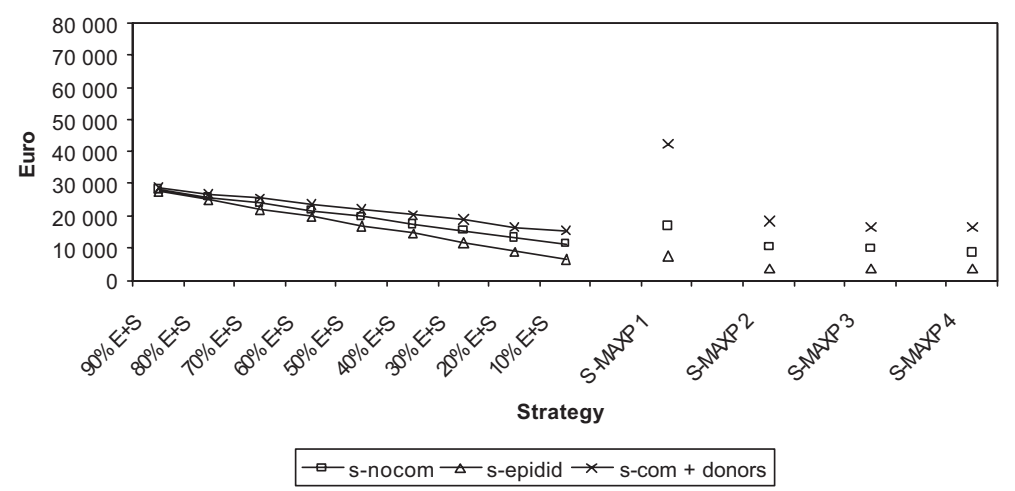

Figure 4. Costs (Euros) for the creation of the cryo-bank in the sheep across strategies $(\% \mathrm{E}+\mathrm{S}=\%$ embryos + semen; S-MAXP $\mathrm{n}=$ semen-only - maximum number of parturitions before culling) and semen cost scenarios.

the percentage of embryos further diminished costs. Decreasing the percentage of embryos from $90 \%$ to $40 \%$ decreased costs by $51 \%, 55 \%, 54 \%, 55 \%$ and $52 \%$, respectively in the horse, cattle, sheep, pig, rabbit and cattle-ET. With $10 \%$ embryos + semen, costs decreased to 3850 Euros in sheep, 3810 in the pig, 360 in the rabbit, and 4480 in cattle-ET. Use of semen-only in the horse required as much as 1027360 Euros (value not reported in Fig. 3). Although female prolificacy of cattle is similar to that of the horse, costs for semen-only banks were much less ranging from $3620(\mathrm{MAXP}=2)$ to $25690(\mathrm{MAXP}=1)$. The main reason for this difference was due to the much greater yield of semen per collection for cattle. The variability of costs was also much greater for the horse.

Figure 4 and Table IV compare in sheep, and in the horse, cattle, pig, rabbit, cattle-ET, respectively, banking costs with the two strategies using semen across the other three semen cost scenarios, s-com + donors, s-nocom, and s-epidid. Comparisons were again limited to cases where breed reconstruction could be achieved within 12 years. These scenarios were more expensive than the s-com scenario (Fig. 3). When costs to buy semen donors were added (s-com + donors), the costs increase substantially in cattle, sheep and pig, and the proportional increase ranged from 1.1 times with $90 \%$ embryos + semen in cattle to 4.6 times with semen-only in the pig. These increments were smaller in the rabbit, where the cost of the donor is low, and in the horse, where the high cost of the semen collection overwhelms the marginal costs to buy donors. Assuming the absence of commercial value for the semen of the breed (s-nocom), banking costs in the horse, cattle, and sheep were intermediate between those under s-com and s-com + donor scenarios. Conversely, in the pig and rabbit, 
Table IV. Costs (Euros) for the creation of the cryo-bank in the horse, cattle, pig, rabbit and cattle-ET, across the strategies embryos + semen (\% of embryos) and semenonly (MAXP $\mathrm{n}=$ maximum number of parturitions before culling) and semen cost scenarios.

\begin{tabular}{|c|c|c|c|c|c|c|}
\hline \multicolumn{2}{|c|}{ Strategy } & Horse & Cattle & Pig & Rabbit & Cattle-ET \\
\hline \multicolumn{7}{|c|}{ Cost scenario: s-nocom } \\
\hline \multirow[t]{3}{*}{ Embryos + semen } & $90 \%$ & 237270 & 41700 & 33550 & 2770 & 41700 \\
\hline & $50 \%$ & 151080 & 34150 & 28140 & 3200 & 34150 \\
\hline & $10 \%$ & & & 22730 & 3630 & 26610 \\
\hline \multirow[t]{2}{*}{ Semen-only } & MAXP 1 & 455630 & 30760 & 20870 & 4100 & 24140 \\
\hline & MAXP 2 & & 24140 & & & 24140 \\
\hline \multicolumn{7}{|c|}{ Cost scenario: s-com + donors } \\
\hline \multirow[t]{3}{*}{ Embryos + semen } & $90 \%$ & 241470 & 44450 & 32090 & 2370 & 44440 \\
\hline & $50 \%$ & 172990 & 46200 & 21870 & 1460 & 46060 \\
\hline & $10 \%$ & & & 11580 & 540 & 47610 \\
\hline \multirow[t]{2}{*}{ Semen-only } & MAXP 1 & 1092270 & 72560 & 10780 & 970 & 47490 \\
\hline & MAXP 2 & & 50500 & & & 47360 \\
\hline \multicolumn{7}{|c|}{ Cost scenario: s-epidid } \\
\hline \multirow[t]{3}{*}{ Embryos + semen } & $90 \%$ & & 39270 & 31510 & & 39270 \\
\hline & $50 \%$ & & 23620 & 19300 & & 23620 \\
\hline & $10 \%$ & & & 7090 & & 7970 \\
\hline \multirow[t]{2}{*}{ Semen-only } & MAXP 1 & & 23250 & 7750 & & 3880 \\
\hline & MAXP 2 & & 3880 & & & 3880 \\
\hline
\end{tabular}

because of the low number of doses of semen required per donor, the strategy s-nocom based on costs for collection was the most expensive. By comparing semen extracted from slaughtered animals (s-epidid) with ejaculated semen (scom), we observed that costs were quite similar in cattle. In sheep, the costs were higher with the strategy embryos + semen but lower with the strategy semen-only. In the pig, s-epidid was from 1.9 (10\% embryos + semen) to 3.3 (semen-only) more expensive than with ejaculated semen. However, the internalisation of logistic and donor's transport costs might make the s-epidid strategy more appealing.

Cost is not the only factor to consider when comparing the use of semenonly with strategies involving the full or partial use of embryos. One must also consider that the semen bank strategy does not allow $100 \%$ reconstruction of 
Table V. Number of years-keeping-female during reconstruction, as a function of strategy and species ${ }^{1}$.

\begin{tabular}{|c|c|c|c|c|c|c|}
\hline Strategy & Cattle & Horse & Sheep & Pig & Rabbit & Cattle-ET \\
\hline Embryos-only & 35.1 & 42.2 & 21.1 & 18.8 & 9.3 & 35.1 \\
\hline \multicolumn{7}{|l|}{ Embryos + semen } \\
\hline \multicolumn{7}{|l|}{$\%$ embryos $^{2}$} \\
\hline 90 & 40.3 & 48.7 & 17.6 & 5.2 & 2.2 & 11.4 \\
\hline 80 & 54.8 & 66.2 & 22.7 & 9.3 & 3.9 & 15.8 \\
\hline 70 & 77.8 & 94.0 & 31.5 & 12.7 & 5.3 & 26.9 \\
\hline 60 & 103.2 & 124.8 & 40.8 & 14.5 & 6.0 & 32.4 \\
\hline 50 & 166.2 & 200.9 & 51.8 & 15.5 & 6.4 & 38.0 \\
\hline 40 & 208.4 & 251.9 & 60.7 & 16.6 & 6.9 & 43.2 \\
\hline 30 & & & 77.1 & 18.3 & 7.6 & 51.2 \\
\hline 20 & & & 77.1 & 25.3 & 10.5 & 66.9 \\
\hline 10 & & & 87.7 & 30.5 & 12.7 & 74.9 \\
\hline \multicolumn{7}{|l|}{ Semen-only } \\
\hline \multicolumn{7}{|l|}{$\mathrm{MAXP}^{3}$} \\
\hline 4 & & & 144.2 & & & \\
\hline 3 & & & 157.3 & & & \\
\hline 2 & 1231.9 & & 240.5 & & & 195.3 \\
\hline 1 & 12877.5 & 15581.5 & 1775.5 & 84.0 & 36.6 & 341.3 \\
\hline
\end{tabular}

the genome. In cattle, cattle-ET and pigs, semen-only was always cheaper than any strategy using embryos, but in some cases differences were very small. In the horse, sheep and rabbit it is worth noting that embryos + semen can be cheaper than the use of semen-only. The economic appeal of embryos in the rabbit has been previously suggested $[9,12]$.

Table $\mathrm{V}$ reports the number of years-keeping-females (Years-FF) during reconstruction, which should allow, by knowing the specific country/breed framework, the estimation of reconstruction costs. Data are limited to cases where breed reconstruction could be achieved within 12 years. With embryosonly, Years-FF ranged from nine (rabbit) to 42 (horse). In sheep, pig and rabbit, Years-FF was, in some cases, lower with embryos + semen than with embryosonly. With semen-only, Years-FF was always higher than with embryos alone or in combination with semen. The importance of reconstruction costs relative to bank creation costs is dubious. First, reconstruction will (hopefully) only be 
necessary in only very rare situations. Also, costs of reconstruction (if needed) will be incurred in the future and must then be discounted to the present, whereas costs for bank creation are immediate. In the horse, embryos $+\mathrm{se}-$ men was associated with both the lowest costs and Years-FF, so the relative importance of bank creation and breed reconstruction is irrelevant.

The costs of storage maintenance were not considered in this paper because to take them into account an arbitrary time horizon of storage should be defined. As a general indication, we can consider a cost of storage that includes liquid nitrogen and tanks, of 0.2 and 0.3 Euro per year, respectively per semen dose and embryo. In this case, cost per year will vary from 20 (rabbit, 10\% embryos + semen) to 121 (cattle, 90\% embryos + semen) Euros considering the strategies embryos-only and embryos + semen, and they can be even 43 times higher with the strategy semen-only when a high number of doses have to be stored (cattle and horse, MAXP = 1). Comparisons among cryo-conservation and in situ or ex situ live schemes will require, besides time horizon of storage, additional assumptions on differences between the profit from farming the average commercial breed and the endangered breed that were not investigated here.

Loss of genetic variability can also be considered a "cost" of breed reconstruction schemes. The material stored in the banks was assumed to be derived from 25 or more unrelated founders, which should guarantee the retention of at least $98 \%$ of the heterozygosity of the donor population. Because of the small population size, during reconstruction with semen-only and embryos + semen, one expects to lose some additional genetic variation. One aim of the reconstruction process should be to minimise this loss and this factor was addressed by Boettcher et al. [2] for banks with embryos. With the strategy embryos + semen, Boettcher et al. [2] observed that an additive genetic relationship among members of the reconstructed population was always below $12 \%$ when applying a strategy of sequential use of males. With the strategy semen-only, when the expected lifetime production of fertile daughters by females is greater than 1, not all founder males can be used at each back-cross generation, and this can lead to consistent losses of founder genetic variation. To avoid this risk, all 25 male founders were used in the last generation [6], allowing the average relationship in the reconstructed population to remain below $3 \%$.

\section{CONCLUSIONS}

The objective of this study was to compare costs of three approaches for creation of gene banks for breed reconstruction, semen-only, embryos-only and 
embryos + semen. The results showed high variation of costs across species and strategies and indicated that the availability and efficiency of reproduction technologies as well as market conditions might substantially change costs among countries. Considering these factors, no single recipe for gene banking was universally superior, and the many options available should be evaluated in the specific contexts. The availability in the future of technologies such as sexing of embryos and semen, low cost in vitro fertilisation, and routine cloning from somatic cells [7] might reduce overall costs. Finally, this study assumed the creation of gene banks for the reconstruction of an extinct population. Other aims, such as storing material as a genetic back-up in case of losses of genetic variation or to create synthetic breeds, should require smaller amounts of genetic material and might be considered when funds are limited.

\section{ACKNOWLEDGEMENTS}

This research work was funded in part by a grant from the Region of Lombardy, Italy. The authors thank Urban Besenfelder, Coralie Danchin-Burge, Cesare Galli, Sipke J. Hiemstra, and Sam Jones for data used to estimate costs underlying the simulation.

\section{REFERENCES}

[1] Blash S., Melican D., Gavin W., Cryopreservation of epididymal sperm obtained at necropsy from goats, Theriogenology 54 (2000) 899-905.

[2] Boettcher P.J., Stella A., Pizzi F., Gandini G., The combined use of embryos and semen for cryogenic conservation of farm mammal genetic resources, Genet. Sel. Evol. 37 (2005) 657-675.

[3] Brem G., Graf F., Kräusslich H., Genetic and economic differences among methods of gene conservation in farm animals, Livest. Prod. Sci. 11 (1984) 65-68.

[4] ERFP, Guidelines for the constitution of national cryopreservation programmes for farm animals, Publication No 1 of the European Regional Focal Point on Animal Genetic Resources, 2003.

[5] FAO, Secondary Guidelines for Development of National Farm Animal Genetic Resources Management Plans, FAO, Rome, 1988.

[6] Gandini G., Pizzi F., Maltecca C., Heinzl E., Pagnacco G., Banche delle risorse genetiche suine: alcuni criteri di ottimizzazione, Zootecnia e Nutrizione Animale 6 (2001) 285-293.

[7] Groeneveld E., A world wide emergency program for the creation of national genebanks of endangered breeds in animal agriculture, AGRI 36 (2005) 1-6.

[8] Hill W.G., Variation in genetic composition in backcrossing programs, J. Hered. 84 (1993) 212-213. 
[9] Joly T., Renard J.P., Coûts des techniques de cryoconservation de la semence et des embryons pour la mise en oeuvre d'une cryobanque chez le lapin, in: Proceedings of 7e Journées de la Recherche Cunicole, 13-14 May 1998, ITAVI et Coll., pp. 37-39.

[10] Labroue F., Loquet M., Guillouet P., Bussière J.J., Glodek P., Wemheuer W., Gandini G., Pizzi F., Delgado J.V., Poto A., Peinado B., Sereno J.R.B., Ollivier L., Pig Semen banks in Europe, in: Ollivier L., Labroue F., Glodek P., Gandini G., Delgado J.V. (Eds.), Characterisation and conservation of pig genetic resources, EAAP Publication No. 104, Wageningen Pers, Wageningen, 2001, pp. 111-122.

[11] Lömker R., Simon D.L., Costs of and inbreeding in conservation of endangered breeds of cattle, in: Proceedings of the 5th World Congress on Genetics Applied to Livestock Production, 7-12 August 1994, Vol. 21, University of Guelph, Guelph, pp. 393-396.

[12] Ollivier L., Renard J.P., The costs of cryopreservation of animal genetic resources, in: Book of Abstract of the 46th Annual Meeting of the European Association for Animal Production, 4-7 September 1995, Wageningen Pers, Wageningen, p. 57.

[13] Persson Y., McGowan M., Söderquist L., Comparison between the sperm morphology in semen samples obtained from yearling beef bulls by transrectal massage of the ampullae and cauda epididymal dissection, Reprod. Dom. Anim. 41 (2006) 233-237.

[14] Rath D., Niemann H., In vitro fertilization of porcine oocytes with fresh and frozen-thawed ejaculated or frozen-thawed epididymal semen obtained from identical boars, Theriogenology 47 (1997) 785-793.

[15] Roughsedge T., Villanueva B., Woolliams J.A., Determining the relationship between restorative potential and size of a gene bank to alleviate the risks inherent in a scrapie eradication breeding programme, Livest. Sci. 100 (2006) 231-241.

[16] Smith C., Estimated costs of genetic conservation of farm animals, in: FAO Animal Production and Health Paper 44/1, FAO, Rome, 1984, pp. 21-30.

[17] Sonesson A.K., Goddard M.E., Meuwissen T.H., The use of frozen semen to minimize inbreeding in small populations, Genet. Res. 80 (2002) 27-30. 